Check for updates

Cite this: RSC Adv., 2019, 9, 17653

Received 23rd March 2019 Accepted 28th May 2019

DOI: 10.1039/c9ra02235j

rsc.li/rsc-advances

\title{
Dual-functional persistent luminescent nanoparticles with enhanced persistent luminescence and photocatalytic activity $\uparrow$
}

\begin{abstract}
Ailijiang Tuerdi and Abdukader Abdukayum (D) *
Dual-functional nanoparticles with near-infrared (NIR) persistent luminescence and sun-light photocatalytic activity are highly desired for medical diagnosis and environmental protection. Here, we report a facile one-step method for simultaneous enhancement of persistent luminescence and photocatalytic activity of the dual-functional persistent luminescent nanoparticles (PLNPs). The $\mathrm{Bi}^{3+}, \mathrm{Cr}^{3+}$ co-doped $\mathrm{ZnGa}_{2} \mathrm{O}_{4}$ PLNPs, which were less than $10 \mathrm{~nm}$ in size, were synthesized by an ethylene glycolassisted hydrothermal method. The persistent luminescence and the photocatalytic activity of the PLNPS were significantly and simultaneously improved via additional doping of $\mathrm{Bi}^{3+}$ in $\mathrm{ZnGa}_{2} \mathrm{O}_{4}: \mathrm{Cr}$. The prepared dual-functional PLNPs have great potential in pollutant photo-degradation and long-term imaging in vivo.
\end{abstract}

\section{Introduction}

The long-lasting phosphorescence (or afterglow) of persistent luminescent materials is an optical phenomenon whereby luminescence can remain for a long time (hours to days) after the excitation source is removed..$^{1-3}$ In recent years, persistent luminescent materials have been drawing increasing attention in many areas, such as emergency signage, traffic signs, lighting, photocatalysis, and medicine..$^{4-7}$ Molecular probes based on persistent luminescent nanoparticles (PLNPs) exhibit a super-long afterglow time and do not need in situ excitation during biomedical imaging, so they completely avoid tissue auto-fluorescence, light scattering, and photo-toxicity originating from the excitation light..$^{8-10}$ PLNPs, alone or in combination with other photocatalysts such as $\mathrm{TiO}_{2}$, have great potential in photocatalysis owing to their potentially increased solar light absorption during day time and subsequent increased solar energy release at night or after the removal of illumination source., ${ }^{3,11}$ Therefore, dual-functional PLNPs with near-infrared (NIR) persistent luminescence and photocatalytic activity have great potential in medical diagnosis and environmental protection.

Zinc gallate $\left(\mathrm{ZnGa}_{2} \mathrm{O}_{4}\right)$ is a cubic normal $\mathrm{AB}_{2} \mathrm{O}_{4}$ spinel crystal semiconductor with the $F d 3 m$ space group..$^{12}$ It is one of the excellent blue-emitting phosphors with wide band gaps $(4.4 \mathrm{eV}$ for $\mathrm{ZnGa}_{2} \mathrm{O}_{4}$ ) and has great potential applications in displays,

Xinjiang Laboratory of Native Medicinal and Edible Plant Resources Chemistry, College of Chemistry and Environmental Sciences, Kashgar University, Kashgar 844007, China. E-mail: abdukadera@sina.com

$\dagger$ Electronic supplementary information (ESI) available. See DOI: 10.1039/c9ra02235j owing to its strong blue emission, better chemical and thermal stability, and excellent cathodoluminescence properties. ${ }^{13}$ $\mathrm{ZnGa}_{2} \mathrm{O}_{4}$ also acts as an excellent photo-catalyst due to its hybridized orbitals of Zn4s4p, Ga4s4p, and band gap, which can improve the mobility of photo-generated electrons and the absorption efficiency of ultraviolet (UV) light., ${ }^{5,14}$

$\mathrm{ZnGa}_{2} \mathrm{O}_{4}$ is also an excellent photoluminescence host material when doped with transition metals, such as Mn-doped $\mathrm{ZnGa}_{2} \mathrm{O}_{4}$ for green emission, and $\mathrm{Cr}^{3+}$-doped $\mathrm{ZnGa}_{2} \mathrm{O}_{4}\left(\mathrm{ZnGa}_{2}-\right.$ $\mathrm{O}_{4}: \mathrm{Cr}$ ) for red or near-infrared (NIR) emission..$^{15}$ In particular, $\mathrm{ZnGa}_{2} \mathrm{O}_{4}: \mathrm{Cr}$ is a bright NIR-emission persistent luminescence phosphor, which is considered a promising optical nanoprobe for in vivo bio-imaging. ${ }^{16-18}$ Co-doping of $\mathrm{ZnGa}_{2} \mathrm{O}_{4}$ or zinc gallogermanate systems with $\mathrm{Cr}^{3+}$ and rare earth ions, such as $\mathrm{Pr}^{3+}$ and $\mathrm{Dy}^{3+}$, can significantly improve the persistent luminescence intensity and afterglow time of PLNPs, because trivalent lanthanide ions with special $4 \mathrm{f}$ electron configurations can provide more efficient trap density and depth. ${ }^{9,19,20}$ However, afterglow time of the $\mathrm{Cr}^{3+}$-doped $\mathrm{ZnGa}_{2} \mathrm{O}_{4}$ is still not long enough for long-term in vivo imaging. Furthermore, the $\mathrm{Cr}^{3+}$ doped $\mathrm{ZnGa}_{2} \mathrm{O}_{4}$ is hardly used on photocatalytic degradation owing to its lower photocatalytic activity, compared to un-doped $\mathrm{ZnGa}_{2} \mathrm{O}_{4}$. Therefore, the development of an effective one-step methodology to simultaneously improve the persistent luminescence and the photocatalytic activity of dual-functional PLNPs are highly desired for pollutant photo-degradation and long-term imaging in vivo. Nevertheless, to the best of our knowledge, no work on simultaneous enhancement of persistent luminescence and photocatalytic activity for $\mathrm{Cr}^{3+}$ co-doped $\mathrm{ZnGa}_{2} \mathrm{O}_{4}$ have been reported so far.

Here, we report a facile one-step method for simultaneous enhancement of persistent luminescence and photocatalytic 
activity of the dual-functional PLNPs. The $\mathrm{Bi}^{3+}, \mathrm{Cr}^{3+}$ co-doped $\mathrm{ZnGa}_{2} \mathrm{O}_{4}$ PLNPs, which were less than $10 \mathrm{~nm}$ in size, were synthesized by an ethylene glycol-assisted hydrothermal method. The NIR persistent luminescence and photocatalytic activity of $\mathrm{Cr}^{3+}$ co-doped $\mathrm{ZnGa}_{2} \mathrm{O}_{4}$ are significantly, and simultaneously, improved by additional doping with $\mathrm{Bi}^{3+}$. The prepared dual-functional PLNPs are promising for in vivo bioimaging and photocatalytic application.

\section{Experimental}

\subsection{Sample preparation}

$\mathrm{Bi}^{3+}, \mathrm{Cr}^{3+}$ co-doped $\mathrm{ZnGa}_{2} \mathrm{O}_{4}$ PLNPs were prepared by an ethylene glycol assisted hydrothermal method. To prepare the $\mathrm{ZnGa}_{1.97} \mathrm{O}_{4}: \mathrm{Cr}_{0.01} / \mathrm{Bi}_{0.02}, 10.0 \mathrm{~mL}$ of ethylene glycol, $3.94 \mathrm{~mL}$ of $\mathrm{Ga}^{3+}\left(0.2 \mathrm{~mol} \mathrm{~L}^{-1}\right), 1 \mathrm{~mL}$ of $\mathrm{Zn}^{2+}\left(0.4 \mathrm{~mol} \mathrm{~L}^{-1}\right), 0.4 \mathrm{~mL}$ of $\mathrm{Cr}^{3+}$ $\left(0.01 \mathrm{~mol} \mathrm{~L}^{-1}\right)$, and $0.8 \mathrm{~mL}$ of $\mathrm{Bi}^{3+}\left(0.01 \mathrm{~mol} \mathrm{~L}^{-1}\right)$ were mixed and stirred at room temperature for $30 \mathrm{~min}$. The $\mathrm{pH}$ of the mixture solution was then adjusted to 9 with aqueous ammonia (15 wt\%) and stirred at room temperature for $1 \mathrm{~h}$. The resulting mixture was transferred to a $20 \mathrm{~mL}$ Teflon-lined stainless-steel autoclave in ambient environment and heated at $170{ }^{\circ} \mathrm{C}$ for $24 \mathrm{~h}$. The autoclave was then allowed to cool to room temperature. The purified products were separated by centrifugation and the NPs were precipitated and washed with distilled water and ethanol and dried in a vacuum oven at $60{ }^{\circ} \mathrm{C}$ for $12 \mathrm{~h}$. Finally, the PLNPs were annealed in air at $1000{ }^{\circ} \mathrm{C}$ for $3 \mathrm{~h}$.

\subsection{Characterization}

X-ray diffraction (XRD) patterns were recorded on a D/max-2500 diffractometer (Rigaku, Japan) using $\mathrm{Cu} \mathrm{K} \alpha$ radiation $(\lambda=$ $1.5418 \AA$ A). Transmission electron microscopy (TEM) and highresolution TEM images were obtained on JEOL-100CX II and JEM-2100F field emission transmission electron microscopes (JEOL, Japan), respectively. The elemental composition of samples was analyzed with an EDAX Genesis XM2 attached to the S-4800 SEM (Hitachi, Japan). X-ray photoelectron spectra (XPS) were recorded on Escalab 250Xi (Thermo Fisher Scientific, USA) X-ray photoelectron spectrometer. The excitation and emission spectra and the long-lasting luminescence decay curves were obtained at room temperature using a F-4500 fluorescence spectrophotometer (Hitachi, Japan). The UV-Vis diffuse reflectance spectra were obtained using a UV-2600 UVVis Spectrophotometer (Shimadzu, Japan).

\section{Results and discussion}

\subsection{Structure and morphology}

Fig. 1 shows the XRD patterns of $\mathrm{ZnGa}_{2} \mathrm{O}_{4}, \mathrm{ZnGa}_{2} \mathrm{O}_{4}: \mathrm{Cr}$, and $\mathrm{ZnGa}_{2} \mathrm{O}_{4}: \mathrm{Cr} / \mathrm{Bi}$. All the peaks are assigned to the $\mathrm{ZnGa}_{2} \mathrm{O}_{4}$ sample with $2 \theta$ at $18.45,30.28,35.7,37.4,43.58,57.56,63.19,65.82$, and 74.72, which were indexed to the (111), (220), (311), (222), (400), (422), (511), (440), and (531) crystal planes, respectively. ${ }^{20}$ All diffraction peaks are consistent with the $\mathrm{ZnGa}_{2} \mathrm{O}_{4}$ spinel phase (JCPDS no. 38-1240). When the contents of $\mathrm{Bi}$ are 0.01 and 0.02, no characteristic peaks of other phases, such as $\mathrm{ZnO}, \mathrm{Ga}_{2} \mathrm{O}_{3}$ and

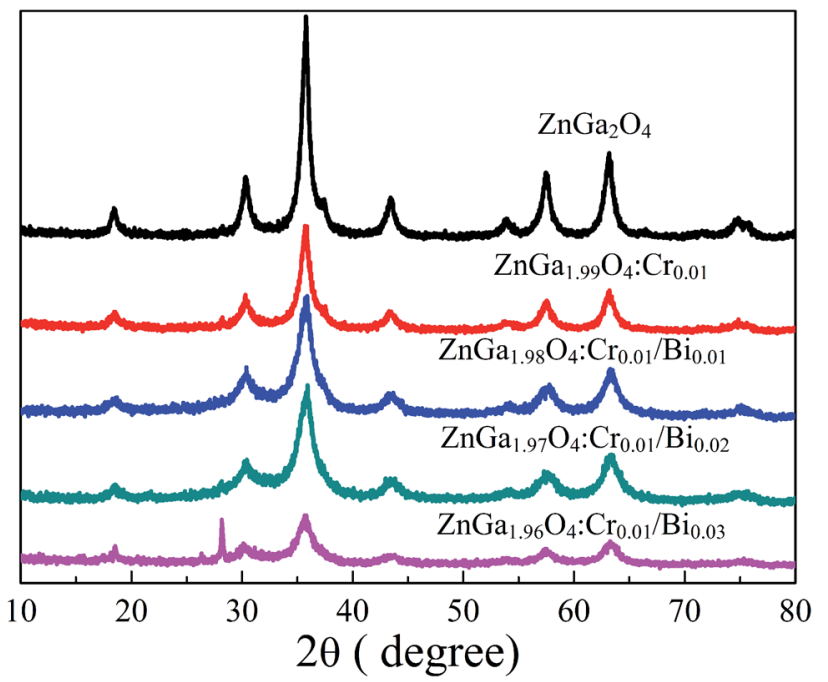

Fig. 1 XRD patterns of $\mathrm{ZnGa}_{2} \mathrm{O}_{4}, \mathrm{ZnGa}_{2} \mathrm{O}_{4}: \mathrm{Cr}$ and $\mathrm{ZnGa}_{2} \mathrm{O}_{4}: \mathrm{Cr} / \mathrm{Bi}$.

$\mathrm{B}_{2} \mathrm{O}_{3}$, were observed, indicating the formation of a pure spinel phase zinc gallate solid solution. When the content of $\mathrm{Bi}^{3+}$ in $\mathrm{ZnGa}_{2} \mathrm{O}_{4}$ :Cr/Bi was increased from 0.02 to 0.03 , we observed a strong peak at $28.01^{\circ}$, which was indexed to the rhombohedral Bi structure. The result indicates that the increasing content of $\mathrm{Bi}^{3+}$ influences the crystal structure of $\mathrm{ZnGa}_{2} \mathrm{O}_{4}$.

Fig. 2a shows TEM image of the as-synthesized $\mathrm{ZnGa}_{1.97^{-}}$ $\mathrm{O}_{4}: \mathrm{Cr}_{0.01} / \mathrm{Bi}_{0.02}$ PLNPs and reveals that the PLNPs are less than $10 \mathrm{~nm}$ in size. The high-resolution TEM analysis shown in Fig. $2 \mathrm{~b}$ indicates that the particles are single crystalline and the distance between the lattice fringes is $4.81 \AA$, which corresponds to the d-spacing of the spinel $\mathrm{ZnGa}_{2} \mathrm{O}_{4}$ (111) lattice planes. The selected-area electron diffraction (SAED) pattern further confirmed that the crystal of as-synthesized $\mathrm{ZnGa}_{1.97^{-}}$ $\mathrm{O}_{4}: \mathrm{Cr}_{0.01} / \mathrm{Bi}_{0.02}$ PLNPs is a pure spinel single crystal (Fig. 2c). The results of EDX analysis are demonstrated that the $\mathrm{ZnGa}_{1.97} \mathrm{O}_{4}: \mathrm{Cr}_{0.01} / \mathrm{Bi}_{0.02}$ PLNPs were composed of only $\mathrm{Zn}, \mathrm{Ga}$, $\mathrm{Cr}, \mathrm{Bi}$, and $\mathrm{O}$ (Fig. 2d). These results revealed that the $\mathrm{ZnGa}_{2} \mathrm{O}_{4}$ crystal structure was successfully doped with Bi and $\mathrm{Cr}$.
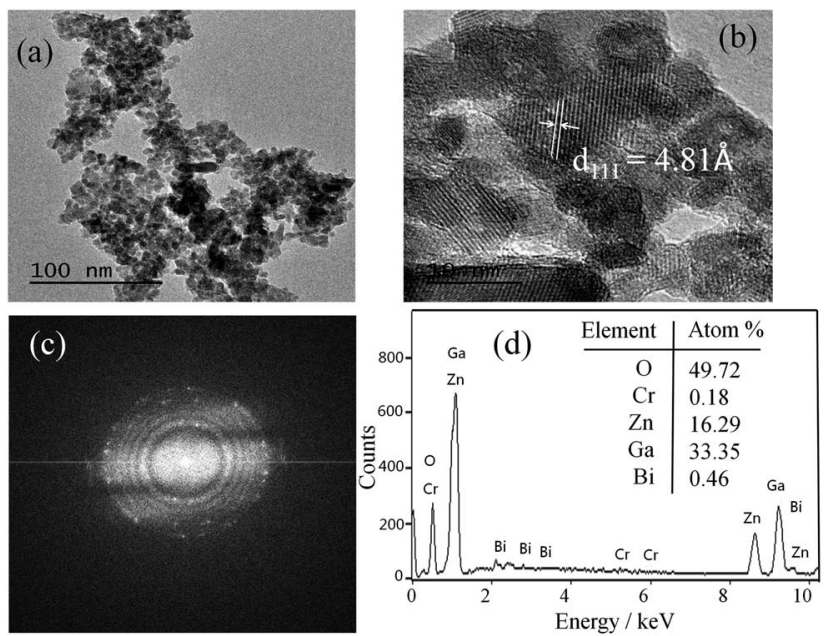

Fig. 2 (a-c) TEM, HR-TEM, SAED images and (d) EDX patterns of $\mathrm{ZnGa}_{1.97} \mathrm{O}_{4}: \mathrm{Cr}_{0.01} / \mathrm{Bi}_{0.02}$. 


\subsection{Persistent luminescence of PLNPs}

Fig. 3 shows the phosphorescence emission spectra of $\mathrm{ZnGa}_{2} \mathrm{O}_{4}: \mathrm{Cr}$ and $\mathrm{ZnGa}_{2} \mathrm{O}_{4}: \mathrm{Cr} / \mathrm{Bi}$ PLNPs at room temperature at an excitation wavelength of $254 \mathrm{~nm}$. $\mathrm{ZnGa}_{2} \mathrm{O}_{4}: \mathrm{Cr}$ produced an intensive NIR emission band peaking at $698 \mathrm{~nm}$ (assigned to ${ }^{2} \mathrm{E} \rightarrow{ }^{4} \mathrm{~A}_{2}$ transition of $\mathrm{Cr}^{3+}$ ions) that superimposes on a broad emission band at 600$800 \mathrm{~nm}$ (assigned to ${ }^{4} \mathrm{~T}_{2} \rightarrow{ }^{4} \mathrm{~A}_{2}$ transition of disordered $\mathrm{Cr}^{3+}$ ions). ${ }^{2}$ The emission spectra of $\mathrm{ZnGa}_{2} \mathrm{O}_{4}: \mathrm{Cr} / \mathrm{Bi}$ are similar to $\mathrm{ZnGa}_{2} \mathrm{O}_{4}: \mathrm{Cr}$, but the emission peaks of $\mathrm{ZnGa}_{2} \mathrm{O}_{4}: \mathrm{Cr} / \mathrm{Bi}$ were slightly red-shifted due to the crystal field strength of $\mathrm{Cr}^{3+}$ centres decreased by additional doping of $\mathrm{Bi}^{3+}$ in $\mathrm{ZnGa}_{2} \mathrm{O}_{4}: \mathrm{Cr}^{21}$ Fig. $\mathrm{S} 1$ (ESI $\dagger$ ) shows the phosphorescence excitation spectra of $\mathrm{ZnGa}_{2} \mathrm{O}_{4}$ : $\mathrm{Cr}$ and $\mathrm{ZnGa}_{2}$ $\mathrm{O}_{4}: \mathrm{Cr} / \mathrm{Bi}$. There are four main absorption bands. The strong band peak around $260 \mathrm{~nm}$ is probably the combination of the $\mathrm{ZnGa}_{2} \mathrm{O}_{4}$ host excitation band and the $\mathrm{O}-\mathrm{Cr}$ charge transfer band. ${ }^{9}$ The bands peaked at approximately $411 \mathrm{~nm}, 471 \mathrm{~nm}$, and $554 \mathrm{~nm}$ and originated from the ${ }^{4} \mathrm{~A}_{2} \rightarrow{ }^{4} \mathrm{~T}_{1}\left(\mathrm{te}^{2}\right)$ transition, the ${ }^{4} \mathrm{~A}_{2} \rightarrow{ }^{4} \mathrm{~T}_{1}\left(\mathrm{t}^{2} \mathrm{e}\right)$ transition, and the ${ }^{4} \mathrm{~A}_{2} \rightarrow{ }^{4} \mathrm{~T}_{2}$ transition originated from the $3 \mathrm{~d}$ intrashell transitions of $\mathrm{Cr}^{3+}$, respectively. ${ }^{2}$

Fig. 4 shows the persistent luminescence emission decay curves of $\mathrm{ZnGa}_{2} \mathrm{O}_{4}: \mathrm{Cr}$ and $\mathrm{ZnGa}_{2} \mathrm{O}_{4}: \mathrm{Cr} / \mathrm{Bi}$ PLNPs, monitored at $698 \mathrm{~nm}$ after being excited by $254 \mathrm{~nm}$ UV light for $5 \mathrm{~min}$. The data represent the persistent luminescence intensity $(I)$ as a function of time $(t)$ and the data recording lasted for $20 \mathrm{~min}$. The persistent luminescence intensity increased as the content of $\mathrm{Bi}$ increased from 0 to 0.02 , but decreased with a further increase from 0.02 to 0.03 . The most intense persistent luminescence was obtained for $\mathrm{ZnGa}_{1.97} \mathrm{O}_{4}: \mathrm{Cr}_{0.01} / \mathrm{Bi}_{0.02}$. The decay curves of the persistent luminescence can be well fitted by the three-exponential eqn (1) as follows: ${ }^{9}$

$$
I(t)=I_{0}+A_{1} \exp \left(\frac{-t}{\tau_{1}}\right)+A_{2} \exp \left(\frac{-t}{\tau_{2}}\right)+A_{3} \exp \left(\frac{-t}{\tau_{3}}\right)
$$

where $I(t)$ is the intensity of persistent luminescence at time $t ; I_{0}$ is the initial intensity of persistent luminescence; $A_{1}, A_{2}$, and $A_{3}$ are constants; $\tau_{1}, \tau_{2}$, and $\tau_{3}$ are derived lifetimes for the exponential components indicating the three different decay processes. The fitting results according to the above formula are

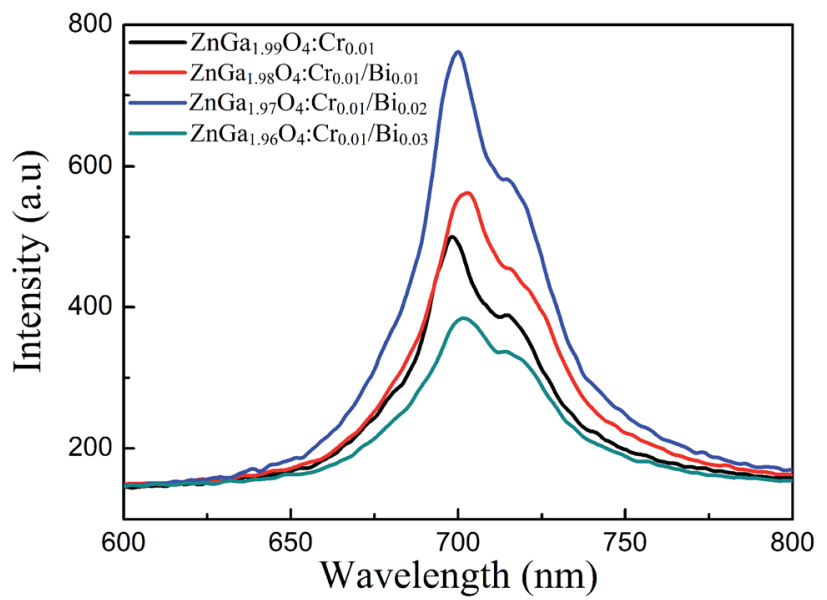

Fig. 3 Phosphorescence emission spectra of $\mathrm{ZnGa}_{2} \mathrm{O}_{4}: \mathrm{Cr}$ and $\mathrm{ZnGa}_{2} \mathrm{O}_{4}: \mathrm{Cr} / \mathrm{Bi}$ at an excitation wavelength of $254 \mathrm{~nm}$.

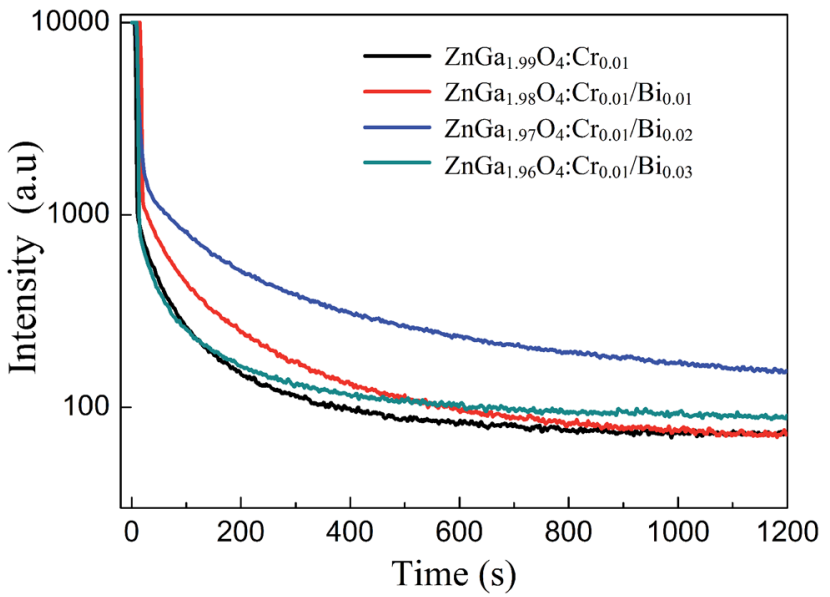

Fig. 4 Afterglow decay curve of $\mathrm{ZnGa}_{2} \mathrm{O}_{4}: \mathrm{Cr}$ and $\mathrm{ZnGa}_{2} \mathrm{O}_{4}: \mathrm{Cr} / \mathrm{Bi}$ after irradiation with a $254 \mathrm{~nm}$ UV lamp for $5 \mathrm{~min}$.

presented in Table $\mathrm{S} 1$ (ESI $\dagger$ ). These average photoluminescence lifetimes $\left(\tau_{\text {av }}\right)$ indicate that the $\mathrm{ZnGa}_{1.97} \mathrm{O}_{4}: \mathrm{Cr}_{0.01} / \mathrm{Bi}_{0.02}$ PLNPs produced a much longer photoluminescence lifetime (32.41 s) than the single $\mathrm{Cr}^{3+}$-doped $\mathrm{ZnGa}_{2} \mathrm{O}_{4}$ PLNPs (9.35 s). The above experimental results indicated that the additional doping of $\mathrm{Bi}^{3+}$ cannot cause remarkable changes in the excitation and emission spectra of $\mathrm{ZnGa}_{2} \mathrm{O}_{4}$ :Cr but can significantly improve the intensity and time of persistent luminescence for $\mathrm{ZnGa}_{2} \mathrm{O}_{4}: \mathrm{Cr}$ PLNPs. Previous work reported that additional doping with $\mathrm{Bi}^{3+}$ in $\mathrm{ZnGa}_{2} \mathrm{O}_{4}$ :Cr can also enhance the persistent luminescence of PLNPs. ${ }^{22,23}$ The $\mathrm{Cr}^{3+}$ prefers to substitute for $\mathrm{Ga}^{3+}$ (with a similar ionic radius) in distorted octahedral coordination in $\mathrm{ZnGa}_{2} \mathrm{O}_{4}: \mathrm{Cr}$. The $\mathrm{Bi}^{3+}$ substituting for $\mathrm{Ga}^{3+}$ can cause a higher periodic lattice distortion in $\mathrm{ZnGa}_{2} \mathrm{O}_{4}: \mathrm{Cr}$, because the radius of $\mathrm{Bi}^{3+}(103 \mathrm{pm})$ is bigger than that of $\mathrm{Ga}^{3+}(62 \mathrm{pm})$. The higher periodic lattice distortion could generate more defects in the $\mathrm{ZnGa}_{2} \mathrm{O}_{4}$ host. ${ }^{24}$ Doping with $\mathrm{Bi}^{3+}$ probably increases the afterglow time of $\mathrm{ZnGa}_{2} \mathrm{O}_{4}$ :Cr PLNPs by producing more hole traps. ${ }^{19}$

\subsection{Photocatalytic activity of PLNPs}

Fig. 5 shows the UV-Vis diffuse reflectance spectra of $\mathrm{ZnGa}_{2} \mathrm{O}_{4}$, $\mathrm{ZnGa}_{2} \mathrm{O}_{4}: \mathrm{Cr}$, and $\mathrm{ZnGa}_{1.97} \mathrm{O}_{4}: \mathrm{Cr}_{0.01} / \mathrm{Bi}_{0.02}$. The $\mathrm{Bi}^{3+}, \mathrm{Cr}^{3+}$ codoped $\mathrm{ZnGa}_{2} \mathrm{O}_{4}$ PLNPs have a broad absorption spectra from UV to visible light ( $670 \mathrm{~nm})$, and the UV-Vis light absorption is remarkably enhanced, compared to $\mathrm{ZnGa}_{2} \mathrm{O}_{4}$ and $\mathrm{ZnGa}_{2} \mathrm{O}_{4}: \mathrm{Cr}$. The broad absorption band of the $\mathrm{Bi}^{3+}, \mathrm{Cr}^{3+}$ co-doped $\mathrm{ZnGa}_{2} \mathrm{O}_{4}$ PLNPs at $450 \mathrm{~nm}$ is associated with the charge transfer band from $\mathrm{Bi}^{3+} 6 \mathrm{~s}^{2}$ to $\mathrm{Bi}^{5+} 6 \mathrm{~s}^{0} .^{25,26}$ We carried out the XPS experiments to verify the existence of $\mathrm{Bi}^{5+}$. The $\mathrm{Bi} 4 \mathrm{f}$ XPS spectrum shows two distinct peaks which were fitted into three peaks at $158.87 \mathrm{eV}$, $160.23 \mathrm{eV}$ and $163.92 \mathrm{eV}$, respectively (Fig. S2 (ESI $\dagger$ )). The peaks of $\mathrm{Bi} 4 \mathrm{f}_{7 / 2}$ at $158.87 \mathrm{eV}$ and $\mathrm{Bi} 4 \mathrm{f}_{5 / 2}$ at $163.92 \mathrm{eV}$ are corresponding to $\mathrm{Bi}(\mathrm{III})$. The peak of $\mathrm{Bi} 4 \mathrm{f}_{7 / 2}$ at $160.23 \mathrm{eV}$ is ascribed to $\mathrm{Bi}(\mathrm{v})$, which indicates existence of the $\mathrm{Bi}^{5+}$ in the $\mathrm{ZnGa}_{1.97} \mathrm{O}_{4}$ :$\mathrm{Cr}_{0.01} / \mathrm{Bi}_{0.02} \cdot{ }^{27,28}$ Band gaps $\left(E_{\mathrm{g}}\right)$ of $\mathrm{ZnGa}_{2} \mathrm{O}_{4}, \mathrm{ZnGa}_{2} \mathrm{O}_{4}: \mathrm{Cr}$, and $\mathrm{ZnGa}_{1.97} \mathrm{O}_{4}: \mathrm{Cr}_{0.01} / \mathrm{Bi}_{0.02}$ were calculated to be approximately $4.38 \mathrm{eV}, 4.45 \mathrm{eV}$, and $2.75 \mathrm{eV}$, respectively (Fig. S3 (ESI $\dagger$ )), according to the following eqn (2): ${ }^{29}$ 


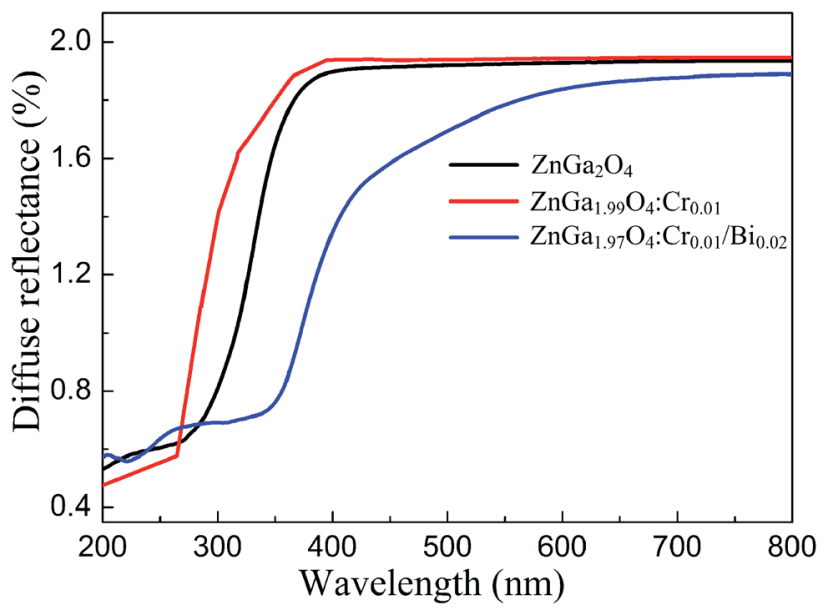

Fig. 5 UV-Vis diffuse reflectance spectra of $\mathrm{ZnGa}_{2} \mathrm{O}_{4}, \mathrm{ZnGa}_{2} \mathrm{O}_{4}: \mathrm{Cr}$ and $\mathrm{ZnGa}_{1.97} \mathrm{O}_{4}: \mathrm{Cr}_{0.01} / \mathrm{Bi}_{0.02}$.

$$
\alpha h v=A\left(h v-E_{\mathrm{g}}\right)^{2}
$$

where $\alpha$ is the absorption coefficient, $h v$ is the photon energy, and $A$ is a constant. The experimental results shows that band gap of the $\mathrm{ZnGa}_{2} \mathrm{O}_{4}$ was slightly increased by doping $\mathrm{Cr}^{3+}$, probably due to the self-reduction effect on $\mathrm{Cr}^{3+}$ ions reduce into lower valence states and the absence of localized states in the band gap. ${ }^{30,31}$ In contrast, the additional doping of $\mathrm{ZnGa}_{2}$ $\mathrm{O}_{4}$ : $\mathrm{Cr}$ with $\mathrm{Bi}^{3+}$ can significantly decrease the band gap of $\mathrm{ZnGa}_{2} \mathrm{O}_{4}$, owing to the electronic structure of $\mathrm{Bi}$ with a unique $6 \mathrm{~s}$ orbital, ${ }^{27,32}$ which has the benefit of increasing solar light absorption in applications of photocatalysis degradation.

Rhodamine $\mathrm{B}(\mathrm{RhB})$ was used as the probe molecule to evaluate the photocatalytic performance of the $\mathrm{Bi}^{3+}, \mathrm{Cr}^{3+}$ codoped $\mathrm{ZnGa}_{2} \mathrm{O}_{4}$ PLNPs. The photo-degradations efficiency of $\mathrm{ZnGa}_{2} \mathrm{O}_{4}, \mathrm{ZnGa}_{2} \mathrm{O}_{4}: \mathrm{Cr}$, and $\mathrm{ZnGa}_{2} \mathrm{O}_{4}: \mathrm{Cr} / \mathrm{Bi}$ for $\mathrm{RhB}$ are shown in Fig. 6. The as-prepared samples were analysed first, to establish an adsorption-desorption equilibrium between the catalyst and the dye molecules. The suspension was stirred in darkness for $40 \mathrm{~min}$, and the samples were then placed under UV light irradiation. The $\mathrm{ZnGa}_{1.97} \mathrm{O}_{4}: \mathrm{Cr}_{0.01} / \mathrm{Bi}_{0.02}$ PLNPs exhibited an excellent photocatalytic activity with a degradation efficiency of 99.2\% after 100 min irradiation with UV light. Experimental results indicate that the photocatalytic activity of the pure $\mathrm{ZnGa}_{2} \mathrm{O}_{4}$ is lower than that of the $\mathrm{Bi}^{3+}, \mathrm{Cr}^{3+}$ co-doped $\mathrm{ZnGa}_{2} \mathrm{O}_{4}$ and higher than that of the single $\mathrm{Cr}^{3+}$ doped $\mathrm{ZnGa}_{2} \mathrm{O}_{4}$ (Fig. 6). The photocatalytic activity of $\mathrm{ZnGa}_{2} \mathrm{O}_{4}$ was suppressed by the doping with $\mathrm{Cr}^{3+}$, because the $\mathrm{Cr}^{3+}$ ions in $\mathrm{ZnGa}_{2} \mathrm{O}_{4}$ act as recombination centres, which can reduce the number and lifetime of the electron-hole pairs. ${ }^{33}$ By contrast, additional doping of $\mathrm{Bi}^{3+}$ in $\mathrm{ZnGa}_{2} \mathrm{O}_{4}$ : $\mathrm{Cr}$ not only enhanced the UV-Vis light absorption of $\mathrm{ZnGa}_{2} \mathrm{O}_{4}$, but also produced more hole trap energy levels, which resulted in more photo-generated electron-holes being captured by traps, thus inhibiting the recombination efficiency of the photo-generated electronholes. ${ }^{24}$ As a consequence, the lifetime of the photo-generated electron-holes and the afterglow time were prolonged.

To investigated the role of reactive oxygen species (ROS) in the degradation process, we carried out the ROS scavenging

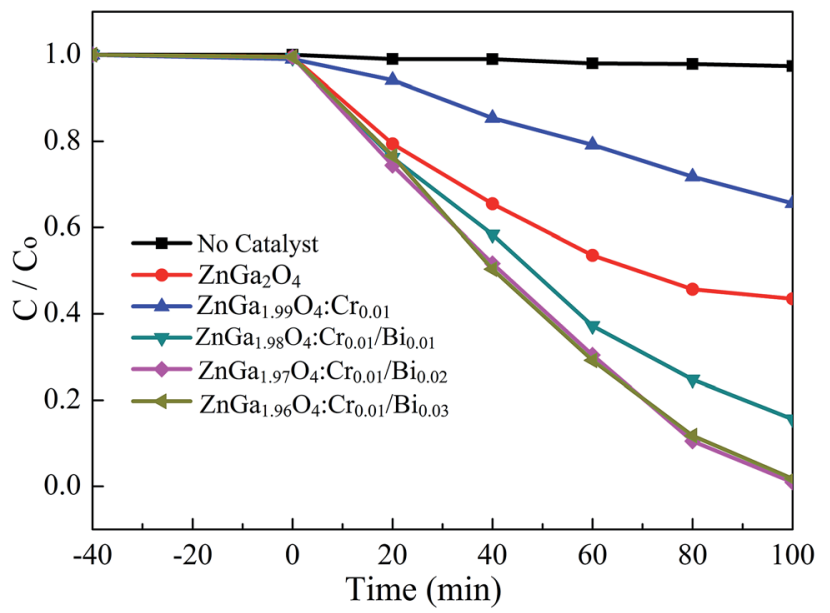

Fig. 6 The photo-degradation efficiency of $\mathrm{ZnGa}_{2} \mathrm{O}_{4}, \mathrm{ZnGa}_{2} \mathrm{O}_{4}: \mathrm{Cr}$ and $\mathrm{ZnGa}_{2} \mathrm{O}_{4}: \mathrm{Cr} / \mathrm{Bi}$ for $\mathrm{RhB}$.

experiments with different scavengers, such as $p$-benzoquinone (BQ) as $\mathrm{O}_{2}{ }^{-}-$scavenger, isopropyl alcohol (IPA) as $\mathrm{HO}^{\cdot}$ scavenger, and ammonium oxalate (AO) as the hole scavenger. ${ }^{34}$ The experimental results shows that the photo-degradation of $\mathrm{RhB}$ is dramatically decreased by adding AO in the RhB solution which indicates that the holes are the most dominant species in the photocatalytic degradation process (Fig. S4 (ESI $\dagger$ )). Compared to $\mathrm{AO}$ and $\mathrm{BQ}$, the addition of IPA result in slight decrease for degradation of $\mathrm{RhB}$, which indicates the $\mathrm{HO}^{\circ}$ radicals are not main contributor for degradation process. The electrons and holes are generated on the surface of PLNPs under light UV radiation. The photogenerated electron-hole pairs reacted with oxygen and water to generate peroxide $\left(\mathrm{O}_{2}{ }^{-}-\right)$ and hydroxyl radicals $\left(\mathrm{HO}^{\circ}\right) .^{35}$ The resulting radicals cause degradation of the organic molecules. This photocatalytic reaction can be represented as follows:

$$
\begin{gathered}
\text { PLNPs }+h v \rightarrow \mathrm{h}_{\mathrm{VB}}^{+}+\mathrm{e}_{\mathrm{CB}}^{-} \\
\mathrm{e}_{\mathrm{CB}}^{-}+\mathrm{O}_{2} \rightarrow \mathrm{O}_{2}^{\cdot-} \\
\mathrm{h}_{\mathrm{VB}}^{+}+\mathrm{H}_{2} \mathrm{O} \rightarrow \mathrm{HO}^{\cdot}+\mathrm{H}^{+} \\
\text {Dye }+\left(\mathrm{O}_{2}^{\cdot-} / \mathrm{HO}^{\cdot}\right) \rightarrow \text { degradation }
\end{gathered}
$$

\section{Conclusions}

The $\mathrm{Bi}^{3+}, \mathrm{Cr}^{3+}$ co-doped $\mathrm{ZnGa}_{2} \mathrm{O}_{4}$ PLNPs were synthesized by an ethylene glycol assisted hydrothermal method. The particle size of the as-prepared PLNPs was less than $10 \mathrm{~nm}$. The photodegradation efficiency of $\mathrm{Bi}^{3+}, \mathrm{Cr}^{3+}$ co-doped $\mathrm{ZnGa}_{2} \mathrm{O}_{4}$ PLNPs for RhB was $99.2 \%$ after 100 min irradiation with UV light. Compared to $\mathrm{ZnGa}_{2} \mathrm{O}_{4}: \mathrm{Cr}$ and un-doped $\mathrm{ZnGa}_{2} \mathrm{O}_{4}$, the additional doping of $\mathrm{Bi}^{3+}$ in $\mathrm{ZnGa}_{2} \mathrm{O}_{4}$ : $\mathrm{Cr}$ not only significantly enhanced the NIR persistence luminescence of the PLNPs, but also remarkably improved the photocatalytic degradation efficiency of $\mathrm{RhB}$. Addition of $\mathrm{Bi}^{3+}$ in $\mathrm{ZnGa}_{2} \mathrm{O}_{4}$ : $\mathrm{Cr}$ may produce 
more trap energy levels, which prolongs the lifetime of the photo-generated electron-holes and the afterglow time. The novel dual-functional PLNPs are promising for in vivo bioimaging and photocatalytic applications.

\section{Conflicts of interest}

The authors declare no conflict of interest.

\section{Acknowledgements}

This work has been supported by the National Natural Science Foundation of China (Grant 21565017) and the Scientific Research Program of the Higher Education Institution of Xinjiang (XJEDU2018I017, XJEDU2016S073).

\section{Notes and references}

1 V. D. E. Koen, P. F. Smet and D. Poelman, Materials, 2010, 3, 2536-2566.

2 Z. Pan, Y. Y. Lu and F. Liu, Nat. Mater., 2011, 11, 58-63.

3 L. Yang, M. Gecevicius and J. R. Qiu, Chem. Soc. Rev., 2016, 45, 2090-2136.

4 V. D. E. Koen, P. F. Smet and D. Poelman, Materials, 2013, 6, 2789-2818.

5 D. R. Li, Y. H. Wang, K. Xu and H. Zhao, RSC Adv., 2015, 46, 20972-20975.

6 S. K. Sun, H. F. Wang and X. P. Yan, Acc. Chem. Res., 2018, 51, 1131-1143.

7 L. Thomas, T. Eliott, R. G. Gonzalo, M. Thomas, V. Bruno, S. Johanne, M. Nathalie, S. Daniel and R. Cyrille, Theranostics, 2016, 6, 2488-2524.

8 L. M. C. Quentin, C. Chanéac, J. Seguin, F. Pellé, S. Matrejean, J. P. J. D. Gourier, M. Bessodes and D. Scherman, Proc. Natl. Acad. Sci. U.S.A., 2007, 104, 92669271.

9 A. Abdukayum, J. T. Chen, Q. Zhao and X. P. Yan, J. Am. Chem. Soc., 2013, 135, 14125-14133.

10 T. Maldiney, A. Bessière, J. Seguin, E. Teston, S. K. Sharma, B. Viana, A. J. Bos, P. Dorenbos, M. Bessodes and D. Gourier, Nat. Mater., 2014, 13, 418-426.

11 S. Yan, J. Wang, H. Gao, N. Wang, H. Yu, Z. Li, Y. Zhou and Z. Zou, Adv. Funct. Mater., 2013, 23, 1839-1845.

12 Y. E. Lee, D. P. Norton, C. Park and C. M. Rouleau, J. Appl. Phys., 2001, 89, 1653-1656.

13 Z. Gu, F. Liu, X. Li, J. Howe, J. Xu, Y. Zhao and Z. Pan, J. Phys. Chem. Lett., 2010, 1, 354-357.

14 S. Yan, S. Ouyang, J. Gao, M. Yang, J. Y. Feng, X. X. Fan, L. J. Wan, Z. S. Li, J. H. Ye, Y. Zhou and Z. G. Zou, Angew. Chem., Int. Ed., 2010, 49, 6400-6404.
15 L. Zou, X. Xiang, M. Wei, F. Li and D. G. Evans, Inorg. Chem., 2008, 47, 1361-1369.

16 A. Bessiere, S. Jacquart, K. Priolkar, A. Lecointre, B. Viana and D. Gourier, Opt. Express, 2011, 19, 10131-10137.

17 J. Liu, T. Lecuyer, J. Seguin, N. Mignet, D. Scherman, B. Viana and C. Richard, Adv. Drug Delivery Rev., 2019, 138, 193-210.

18 A. Abdukayum, C. X. Yang, Q. Zhao, J. T. Chen, L. X. Dong and X. P. Yan, Anal. Chem., 2014, 86, 4096-4101.

19 T. Maldiney, A. 1. Lecointre, B. Viana, A. 1. Bessière, M. Bessodes, D. Gourier, C. Richard and D. Scherman, J. Am. Chem. Soc., 2011, 133, 11810-11815.

20 A. Abdukayum, A. Tuerdi, R. Abdurahman, M. Tursun and N. Nurmat, J. Inorg. Mater., 2016, 31, 1363-1369.

21 Y. Li, Y. Li, R. Chen, K. Sharafudeen, S. Zhou, M. Gecevicius, H. Wang, G. Dong, Y. Wu, X. Qin and J. Qiu, NPG Asia Mater., 2015, 7, e180.

22 Y. Zhuang, J. Ueda and S. Tanabe, Appl. Phys. Express, 2013, 6, 052602.

23 W. B. Dai, Y. F. Lei, S. Ye, E. H. Song, Z. Chen and Q. Y. Zhang, J. Mater. Chem. B, 2016, 4, 1842-1852.

24 L. Li, K. Xu, Y. Wang, Z. Hu and H. Zhao, Opt. Mater. Express, 2016, 6, 1022-1030.

25 H. Mizoguchi, H. Kawazoe, H. Hosono and S. Fujitsu, Solid State Commun., 1997, 104, 705-708.

26 Y. X. Zhuang, J. Ueda and S. Tanabe, Opt. Mater. Express, 2012, 2, 1378-1383.

27 A. Y. Teterin, Y. A. Teterin, K. I. Maslakov, V. G. Yarzhemskĭ̌, S. E. Sverchkov, B. I. Denker, B. I. Galagan, L. D. Iskhakova, L. I. Bulatov, V. V. Dvoľrin, V. M. Mashinskil̆, A. A. Umnikov, A. N. Gur'yanov, V. I. Nefedov and E. M. Dianov, Dokl. Phys., 2008, 53, 566-570.

28 S. Bagwasi, Y. Niu, M. Nasir, B. Tian and J. Zhang, Appl. Surf. Sci., 2013, 264, 139-147.

29 Y. B. Cui and J. F. Luan, J. Environ. Sci., 2015, 29, 51-61.

30 S. K. Kushwaha, K. K. Maurya, D. Haranath and G. Bhagavannarayana, J. Appl. Crystallogr., 2011, 44, 10541061.

31 y. zhuang, J. Ueda, S. Tanabe and P. Dorenbos, J. Mater. Chem. C, 2014, 2, 5502-5509.

32 X. C. Meng and Z. S. Zhang, J. Mol. Catal. A: Chem., 2016, 423, 533-549.

33 L. Li, Y. H. Wang, H. Li, H. J. Huang and H. Zhao, RSC Adv., 2015, 5, 57193-57200.

34 B. M. Pirzada, Pushpendra, R. K. Kunchala and B. S. Naidu, ACS Omega, 2019, 4, 2618-2629.

35 K. Mageshwari, R. Sathyamoorthy and J. Park, Powder Technol., 2015, 278, 150-156. 